\title{
Percepção de docentes de Biologia sobre o sistema sanguíneo ABO e elaboração de modelo didático como ferramenta para o ensino-aprendizagem em Genética
}

\author{
Perception of Biology teachers related to the $\mathrm{ABO}$ system and elaboration of the teaching model as \\ a tool for teaching-learning in Genetics \\ Percepción de profesores de Biología sobre el sistema sanguíneo ABO y elaboración de un modelo \\ didáctico como herramienta de enseñanza-aprendizaje en Genética
}

\section{Resumo}

O presente artigo teve como objetivo conhecer as percepções de docentes de biologia em relação à genética e, em específico, à temática do Sistema $\mathrm{ABO}$, bem como viabilizar uma ferramenta didática para melhor trabalhar esse conteúdo em sala de aula. O contato com os docentes ocorreu através de aplicativo de mensagens gratuito (WhatsApp) e aceite do Termo de Consentimento Livre e Esclarecido. Os participantes preencheram um formulário online semiestruturado com perguntas referentes à genética e ao conteúdo Sistema $\mathrm{ABO}$, disponibilizado através do aplicativo WhatsApp. O trabalho em questão também propôs a construção de um modelo didático relacionado ao sistema $\mathrm{ABO}$, com o objetivo de facilitar o processo de ensino-aprendizagem deste conteúdo. Responderam à pesquisa 26 docentes, e nas respostas observou-se que, para a maioria, o conteúdo de genética foi trabalhado de forma inadequada e não contribuiu muito para sua formação durante a graduação. Além disso, afirmaram que a maior dificuldade em genética se refere aos cálculos utilizados na disciplina. Em relação ao sistema ABO, a maioria dos docentes afirmou gostar de ministrar o conteúdo, mas sente dificuldade por conta da falta de materiais didáticos para otimizar o ensino do mesmo. Por fim, a maioria dos docentes aprovou o modelo didático confeccionado durante a pesquisa e declaram interesse na sua utilização desse modelo, afirmando que o mesmo contribui com o processo de ensino-aprendizagem dos discentes.

Palavras-chave: Genética; Modelo interativo; Sistema sanguíneo ABO; Ensino.

\section{Abstract}

This article known the Biology teachers perceptions in relation to genetics as a whole and specifically to the ABO System content, as well as enabling a didactic tool to better work on this content in the classroom. The contact with the teachers occurred through free messaging application (WhatsApp). Research participants electronically signed the Free and Informed Consent Form and filled out a semi-structured online form (via Google Forms), made available through the WhatsApp application. The work in question also proposed to build a didactic model related to the ABO 
system, with the objective of facilitating the process of teaching and learning this content. Twenty-six teachers responded to the survey, and in the responses, it was observed that, for the majority, the content of genetics was worked inappropriately and did not contribute much to their training during graduation. Additionally, they stated that the greatest difficulty in genetics refers to the calculations used in the discipline. Regarding the ABO system, most teachers like to teach the content, but they experience difficulty due to the lack of didactic materials to optimize the teaching of the content in question. Finally, most teachers approved the didactic model made during the research and declared interest in using this model, stating that it contributes to the teaching-learning process of students. From this, it is concluded that, although teachers like the content, there are difficulties in the teaching-learning process of the ABO system, in addition to the use of other methods for teaching genetics.

Keywords: Interactive model; Genetics; ABO blood system; Teaching.

\section{Resumen}

Este artículo tuvo como objetivo comprender las percepciones de los profesores de biología en relación a la genética y, en particular, a la temática del Sistema ABO, así como brindar una herramienta didáctica para trabajar mejor este contenido en el aula. El contacto con los profesores se realizó a través de una aplicación de mensajería gratuita (WhatsApp) y aceptación del Término de Consentimiento Libre e Informado. Los participantes completaron un formulario en línea semiestructurado con preguntas sobre genética y el contenido del Sistema ABO, disponible a través de la aplicación WhatsApp. El trabajo en cuestión también propuso la construcción de un modelo didáctico relacionado con el sistema $\mathrm{ABO}$, con el fin de facilitar el proceso de enseñanza-aprendizaje de estos contenidos. Respondieron a la encuesta 26 profesores, y en las respuestas se observó que, para la mayoría, el contenido genético fue abordado de manera inadecuada y no contribuyó mucho a su formación durante la graduación. Además, afirmaron que la mayor dificultad en genética se refiere a los cálculos utilizados en el curso. En relación al sistema ABO, la mayoría de los profesores dijeron que les gusta enseñar los contenidos, pero les resulta difícil debido a la falta de materiales didácticos para optimizar su enseñanza. Finalmente, la mayoría de los profesores aprobaron el modelo didáctico creado durante la investigación y manifestaron su interés en utilizar este modelo, manifestando que contribuye al proceso de enseñanza-aprendizaje de los estudiantes.

Palabras clave: Genética; Modelo interactivo; Sistema sanguíneo ABO; Enseñanza.

\section{Introdução}

A disciplina Biologia tem como objeto de estudo os fenômenos da vida, caracterizados por um conjunto de processos organizados e integrados que são trabalhados desde o nível celular até a interação dos organismos entre si e com o meio em que vivem (Brasil, 1999). Para o ensino médio, o currículo de Biologia acaba desafiando o docente a trabalhar diferentes conceitos no que se refere à diversidade da vida, o que por vezes se distancia do cotidiano dos alunos (Duré et al., 2018); um exemplo são os conteúdos de genética, que apesar de ter ganhado destaque em discussões acadêmicas, apresenta-se como uma disciplina complexa para muitos discentes (Sousa et al., 2016). Assim, torna-se necessário o delineamento de técnicas que visem aprimorar as estratégias metodológicas de ensino, de modo que o alunado seja exposto a situações que possibilitem aos mesmos a análise e interpretação dos dados (Augusto \& Basilio, 2018).

O estudo da genética é complexo e engloba conhecimentos de outras disciplinas, tal como a matemática e a química o que acaba dificultando a assimilação pelos discentes. Nesse sentido, e para que o aluno apresente um aprendizado mais significativo, é necessário que os conteúdos sejam trabalhados de forma interdisciplinar. Um exemplo disso centra-se naqueles conteúdos relacionados à biologia celular e/ou à probabilidade, os quais refletem diretamente na Genética (Sousa et al., 2016). Além disso, o discente também precisa compreender, os princípios básicos da replicação, transcrição e tradução, como ocorrem as mutações, sua importância e os possíveis malefícios associados a elas (Lucas, 2015).

Inserido nas subáreas da Genética, o estudo relacionado aos antígenos das células sanguíneas (sistema ABO) é muito relevante e do interesse dos estudantes do Ensino Médio (Bonadio et al., 2015) e muitos docentes recorrem a aulas de laboratório para demonstrar a tipagem sanguínea e fixar melhor o conteúdo. Essa atividade prática possibilita que os estudantes simulem de forma simples e segura as reações que acontecem durante o procedimento de identificação do grupo sanguíneo do sistema ABO (Fonseca \& Tartarotti, 2017); entretanto, muitas vezes os docentes da Educação Básica não têm acesso a esses materiais e/ou laboratórios, necessitando de outros meios para fixação desses assuntos. 
A Educação Básica ainda é fortemente marcada pela presença do ensino tradicional, no qual muitos professores recorrem apenas ao livro para ministrarem suas aulas, ignorando a necessidade de demonstrações práticas e da contextualização dos conteúdos com a realidade dos alunos. O livro deve servir como apoio para a prática docente, não devendo ser considerado o único meio de aprendizado, tendo em vista que não é possível abordar todas as questões de forma contextualizada (Tompo et al., 2016). Nessa perspectiva, o professor deve ser o mediador do conhecimento, buscando a atualização contínua e meios para tornar as informações mais acessíveis aos alunos (Brasil, 2017).

Infelizmente, muitos alunos não compreendem informações importantes no que diz respeito aos conteúdos trabalhados nas aulas de Biologia (Pierce, 2016), principalmente em relação ao ensino de Genética, que ainda apresenta-se muito conceitual e abstrata, sendo necessárias práticas didáticas que auxiliem no ensino-aprendizagem (Souza et al. 2017). Quando aplicadas de maneira eficiente, tais atividades auxiliam a assimilação do conteúdo teórico e possibilitam uma maior interação do aluno com o conhecimento (Nícolas \& Paniz, 2016).

Neste contexto, o presente estudo justifica-se pela necessidade do desenvolvimento de pesquisas que evidenciem a qualidade do ensino de Genética no Educação Básica, e para a produção de modelos didáticos que sejam instrumentos valiosos para uma abordagem interdisciplinar, motivante e significativa dos conteúdos de Genética, com enfoque no Sistema sanguíneo $\mathrm{ABO}$.

\section{Metodologia}

A pesquisa em questão possui finalidade básica, com natureza observacional, abordaguem quali-quantitativa, sendo também caracterizada como pesquisa de campo (Fontelles et al., 2009). Esta foi aplicada a professores da Educação Básica da Rede Pública de Ensino do Estado do Piauí, no município de Uruçuí, em escolas de Ensino Médio que administram conteúdos de Genética no $3^{\circ}$ ano. O contato com os docentes ocorreu por meio do aplicativo de mensagens gratuito WhatsApp, em conformidade com o isolamento social recomendado pela Organização Mundial de Saúde (OMS) em consequência da pandemia da COVID-19. Todos os professores que aceitaram participar do estudo assinaram o Termo de Consentimento Livre e Esclarecido (TCLE), que contém os objetivos da pesquisa, o anonimato das respostas dos participantes, e a divulgação científica dos resultados obtidos pelos pesquisadores.

Para a coleta de dados foi utilizado um formulário semiestruturado, produzido por meio da plataforma Google Forms, que foi disponibilizado através de um link de acesso direto aos docentes pelo aplicativo WhatsApp. A utilização do Google Forms caracteriza-se como um meio economicamente viável, especialmente por não haver custos e pela possibilidade de ser acessado em vários aparelhos eletrônicos, tais como computadores, smartphones, entre outros (Carmo, 2018). O questionário foi composto por 19 questões objetivas e uma questão subjetiva, divididas em três seções: a primeira relacionada ao perfil dos docentes (sexo, idade, pós-graduação e experiência); a segunda relacionada ao ensino de genética (avaliação, dificuldades, afinidades), e; a terceira seção, relacionada ao ensino do conteúdo de sistema $\mathrm{ABO}$ e a percepções dos partícipes no que diz respeito à utilização de modelos didáticos.

A partir das respostas dos docentes, bem como de uma revisão de literatura acerca do tema, percebeu-se a necessidade de construção de um modelo didático com o objetivo de facilitar o processo de ensino-aprendizagem do conteúdo de sistema ABO. Foi produzido um modelo didático que permitisse a ampliação e melhor visualização de estruturas - tais como os antígenos das hemácias - tudo feito com materiais baratos e que poderia ser replicado pelos docentes.

Para a criação do modelo (Figura 1) foi feita uma maquete interativa da representação das hemácias, na qual estavam presentes as estruturas biológicas da determinação sanguínea, os antígenos. Na elaboração da célula foi usado um tecido vermelho, representando a cor das hemácias, e dentro desse tecido foi inserido algodão apenas na periferia da célula, formando uma pequena cavidade central, para simular a forma da célula e a ausência de seu núcleo. Os antígenos foram representados 
por alfinetes, sendo o de haste amarela e cabeça branca o correspondente do antígeno A; o alfinete de cabeça preta e haste amarela o representante do antígeno B; e os alfinetes sem cabeça, representantes do antígeno H, presente no tipo sanguíneo $\mathrm{O}$.

Para a representação dos vasos condutores, por onde passa o sangue, foi utilizado um cano de calha com ímãs para fixação dos anticorpos, feitos em metal. Os anticorpos de cor branca representam o grupo anti-A, e os de cor preta representam os anticorpos anti-B. A partir disso, os alunos têm a chance de visualizar as estruturas que estão presentes nas hemácias e no plasma de cada tipo sanguíneo, conforme observado na Figura 1.

Figura 1 - Modelo didático criado para o ensino do conteúdo de Genética - dos tipos sanguíneos sistema ABO (AB, A, B e O) - com representação dos vasos sanguíneos (calha cinza), das hemácias (células em vermelho), dos antígenos A (alfinetes brancos), dos antígenos B (alfinetes pretos); dos antígenos $\mathrm{H}$ (alfinetes sem cabeça), e dos anticorpos ao redor das células (cinza é anti-A, preto é anti-B).

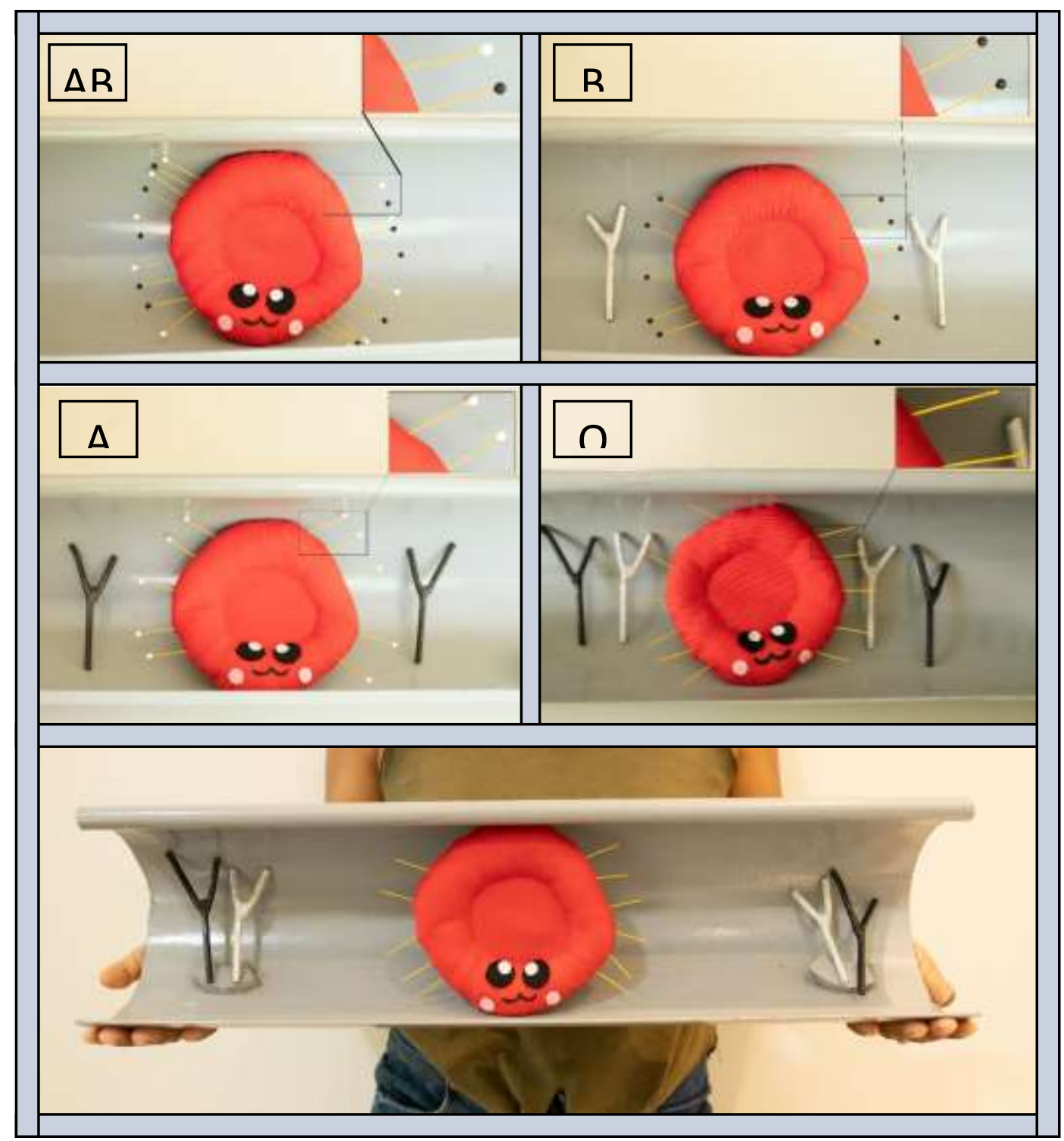

Fonte: Autores (2021).

\section{Resultados e Discussão}

Participaram da pesquisa 26 docentes que lecionaram o conteúdo de Genética nas escolas da Rede Pública de Ensino Médio do município de Uruçuí-Piauí, no ano de 2020. Dentre os partícipes, 15 eram do sexo feminino (58\%) e 11 do sexo 
masculino (42\%). Observou-se que 35\% do total de docentes tinham entre 20 e 29 anos; e 65\%, entre 30 e 39 anos. Quanto ao nível de formação superior desses profissionais, 96\% concluíram a graduação. Apenas 4\% não concluíram a graduação, contrariando o que preconiza a Lei de Diretrizes e Bases da Educação Brasileira - LDB (Lei 9394/96) em seu Art. 62, que afirma que, para o exercício do magistério na Educação Básica, o docente precisará de curso superior e de licenciatura em Universidades e Institutos Superiores de Educação (Brasil, 1996). Quanto ao nível de formação na pós-graduação, uma significativa parcela dos participantes (72\%) possuem pós-graduação concluída, sendo quatro (15\%) Especialistas, cinco (19\%) Mestres e sete (27\%) Doutores, conforme dados da Figura 2. Do total de docentes, 38\% não realização formação em nível de pós-graduação, resultados que se assemelham aos de Medeiros et al. (2017), que observaram uma significativa presença de professores sem pós-graduação em escolas do município de Jaguaribe, estado do Ceará, Brasil.

Figura 2 - Formação dos docentes participantes do estudo, em nível de pós-graduação.

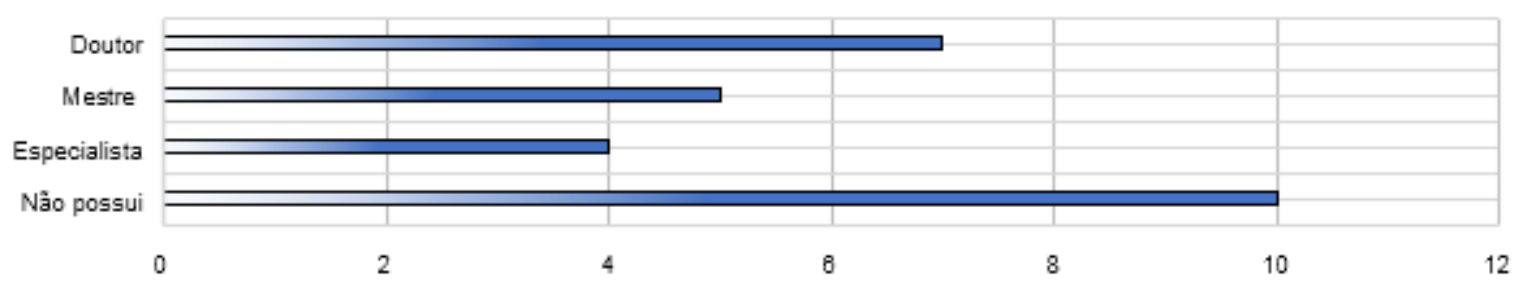

Fonte: Autores (2021).

De modo mais abrangente, no que se refere às disciplinas que os participantes normalmente ministram, $58 \%$ dos docentes afirmaram trabalhar somente dentro da sua área de formação; os outros $42 \%$, ministram aulas de temas diferentes de suas especialidades. Lucas et al. (2016), ao realizarem um estudo em escolas municipais do estado de Mato Grosso, Brasil, observaram que de um total de 23 professores, oito afirmaram ministrar aulas de outras disciplinas, fora de sua área de formação. Nesse contexto, observa-se que, infelizmente, ainda há uma significativa parcela de professores trabalhando na Educação Básica sem uma formação específica, o que acaba influenciando negativamente na qualidade do ensino.

Os professores que participaram do estudo apresentaram diferentes itinerários de experiência docente. Assim, para melhor interpretar os dados coletados, a Figura 3 mostra uma escala de tempo, da atuação dos participantes na Educação Básica: entre 1-5 anos, 6-10 anos, 11-15 anos, 16-20 anos e mais de 20 anos. Nesse contexto, foi possível o registro de 14 professores (54\%) com experiência em sala entre 1-5 anos; três (11\%) entre 6-10 anos; oito (31\%) entre 11-15 anos; e apenas um (4\%) com experiências entre 16-20 anos. Logo, nenhum dos professores leciona há mais de 20 anos. Para Valente (2019), diversos fatores podem influenciar diretamente a atuação do professor, sendo um deles o tempo de docência que está relacionado a uma maior familiaridade com seu campo de atuação. Apesar disso, ressalta-se aqui a trajetória dos docentes em formação, haja vista que os mesmos, em suas diferentes etapas de estágio supervisionado, também aprendem metodologias ativas para posterior atuação profissional.

Figura 3 - Experiência profissional dos docentes participantes da pesquisa.

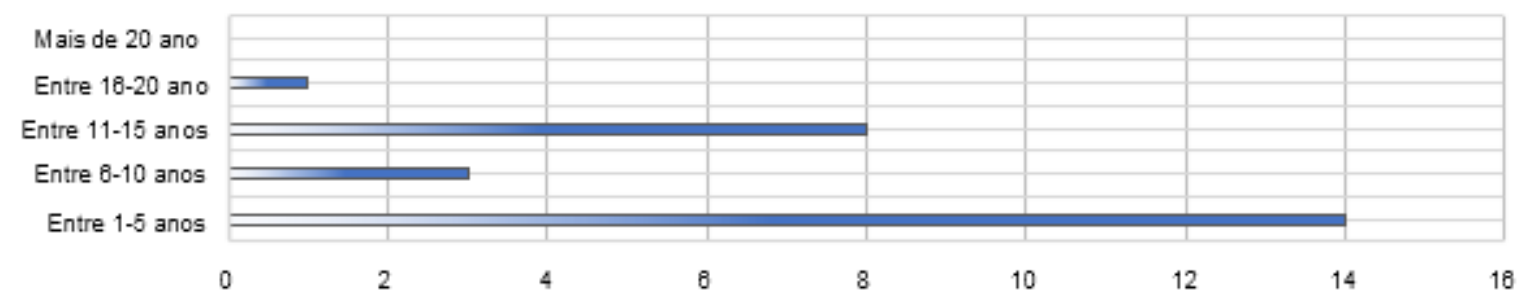

Fonte: Autores (2021). 
Quando questionados se tinham alguma formação relacionada à área de Genética, 11 docentes (42\%) responderam que possuíam e 15 (58\%) que não. Os partícipes foram questionados, também, sobre a forma que a disciplina de Genética havia sido trabalhada ao longo da sua graduação. Observou-se que uma grande parte dos professores (50\%) analisou que a disciplina de genética foi trabalhada de forma inadequada, não contribuindo muito para a sua formação; $31 \%$ dos docentes responderam que a disciplina genética foi muito bem trabalhada, e 19\% responderam que foi bem trabalhada, porém não foi o suficiente para o aprendizado. Assim como em nosso estudo, Kenski (2007) e Silva (2010) discutiram em seus trabalhos a forma como a disciplina de Genética deve ser trabalhada na graduação. Isso evidencia a necessidade de se repensar as estratégias metodológicas para se trabalhar com essa disciplina, tanto na graduação quanto na própria Educação Básica.

Os docentes foram indagados se gostavam ou não de ministrar os assuntos de Genética e, de acordo com as respostas, 49\% responderam sim, "que é um dos conteúdos que mais gostam"; 38\% responderam talvez "não acham a disciplina ruim, porém não têm afinidade"; 13\% responderam que "é um dos conteúdos que menos gosto de trabalhar". Teodoro (2017) faz uma longa reflexão sobre os conteúdos que mais amedrontam os professores na Educação Básica, seja pela dificuldade em relacionar o conteúdo com a realidade do discente, ou mesmo em compreender o próprio conteúdo. Para o autor, os professores têm mais dificuldade em ensinar os temas relacionados à Bioquímica, Genética, Biologia Celular, Árvores filogenéticas e Evolução.

Em relação às principais dificuldades que os alunos possuem no conteúdo de Genética, $31 \%$ dos participantes afirmaram que a maior dificuldade é o fato de o discente "não estudar o suficiente, dificultando a compreensão"; $23 \%$ relataram que está relacionada à "dificuldade dos termos técnicos em Genética"; $42 \%$ associaram à "dificuldade em relação aos cálculos matemáticos" e apenas $4 \%$ relacionara à "forma que a disciplina é ministrada em sala de aula". Nenhum professor marcou a opção relacionada à infraestrutura da escola ou que os alunos possuem pouca ou nenhuma dificuldade (Tabela 1). Dessa forma, reafirma-se que as dificuldades em Genética são bem corriqueiras na Educação Básica e que o docente deve dispor e utilizar das mais diversas metodologias que estiverem ao seu alcance, visando minimizar as inúmeras dificuldades que ainda permeiam o ensino dessa disciplina.

Tabela 1 - Dificuldades dos alunos em relação ao conteúdo de genética de acordo com o relato dos participantes da pesquisa.

\begin{tabular}{|c|c|c|}
\hline Respostas & Professores & $\%$ \\
\hline Não estudam o suficiente, o que dificulta a compreensão & 8 & $31 \%$ \\
\hline Os termos Técnicos são difíceis de aprender e memorizar & 6 & $23 \%$ \\
\hline Os cálculos relacionados à dificuldade em matemática & 11 & $42 \%$ \\
\hline A forma como a disciplina é trabalhada em sala de aula & 1 & $4 \%$ \\
\hline A infraestrutura da escola em que atuam & - & - \\
\hline Os alunos possuem pouca ou nenhuma dificuldade & - & - \\
\hline
\end{tabular}

Fonte: Autores (2021).

No que se refere ao nível de aprendizagem dos alunos na disciplina de Genética, os docentes foram questionados levando-se em consideração os seguintes critérios: ruim (8\%), regular (65\%), boa (23\%) e ótima (4\%) (Figura 4). A Genética encontra-se inserida no contexto tecnológico com diversos avanços científicos na área de Biologia Molecular. No entanto, inúmeros estudos evidenciam que a utilização de livros didáticos como a única fonte para as aulas, muitas vezes, não supre de forma efetiva as necessidades dos docentes/discentes (Soares et al., 2011), havendo a necessidade de materiais complementares.

Uma alternativa para estreitar a relação entre o conteúdo e a realidade dos alunos, seria a realização de aulas mais interativas. Entretanto, o cenário das escolas públicas brasileiras ainda apresenta uma significativa deficiência no que diz respeito à infraestrutura e/ou recursos disponíveis para realização de aulas práticas (Cipriano et al., 2019), o que acaba 
desmotivando tanto o professor quanto o próprio aluno. Nesse contexto, justificam-se os resultados observados, especialmente no que diz respeito à aprendizagem de Genética pelos discentes, tendo em vista que, sem uma real motivação, o rendimento do aluno tende a declinar e, consequentemente, o aprendizado torna-se bem mais difícil.

Figura 4 - Avaliação dos docentes participantes da pesquisa sobre a aprendizagem do conteúdo de Genética.

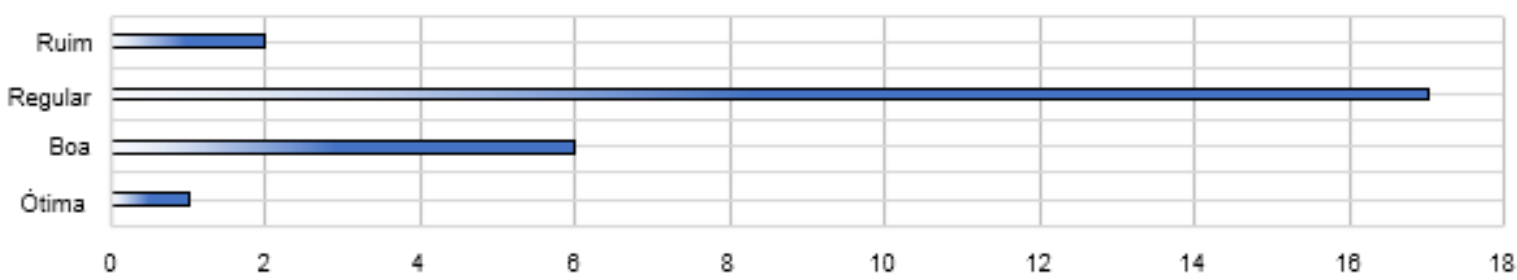

Fonte: Autores (2021).

Os professores foram indagados sobre quais eram as temáticas de Genética em que percebiam uma maior dificuldade por parte dos alunos. De acordo com as respostas, foi possível o registro dos seguintes conteúdos: Genes Ligados (35\%), $2^{\mathrm{a}}$ Lei de Mendel (23\%), Epistasia (15\%), Sistemas Sanguíneos (15\%), Herança Sexual (8\%) e Herança Monogênica (4\%). Segundo Linhares (2013), conceitos como "gene", "cromossomos", "alelos", entre outros termos da Genética Molecular, não são compreendidos pela maioria dos alunos e tal situação está associada à falta de atualização dos conteúdos didáticos e da formação continuada dos professores, o que traz consigo o declínio no aprendizado da Genética. Para Cirne (2013), modelos didáticos, jogos e diversas atividades lúdicas favorecem uma melhor interação professor-aluno e, consequentemente, melhoram o aprendizado. Assim, essas técnicas mostram-se como alternativa para o melhoramento do ensino de Genética, proporcionando uma forma de prender a atenção dos alunos e, com isso, trazer os aspectos práticos para dentro da sala de aula.

Quanto aos conteúdos voltados para o sistema $\mathrm{ABO}, 92 \%$ dos participantes afirmaram que gostam de abordar a temática supracitada em suas aulas. Em contrapartida, $8 \%$ dos docentes afirmaram que não se sentem seguros ou não gostam de ministrar esse conteúdo. $\mathrm{O}$ ensino sobre sistema $\mathrm{ABO}$ é de grande valia, visto que a explicação deste conteúdo aos alunos tem como fundamento o esclarecimento dos diferentes tipos sanguíneos, tais como a aplicação de princípios biológicos que auxiliam em critérios preliminares relativos à saúde (possibilidade de transfusões saguíneas), no suporte em análises jurídicas, conforme a natureza do ato em determinadas situações, além de questões de avaliação da paternidade (Arruda, 2013).

Sobre a avaliação da aprendizagem dos alunos em relação ao sistema ABO, 65\% dos entrevistados a classificaram como ruim; $27 \%$ responderam regular; $4 \%$ analisaram a avaliação de aprendizagem dos alunos como boa; e os outros $4 \%$ responderam como ótima. É perceptível que a maioria dos professores estão insatisfeitos com o aprendizado dos seus alunos no que diz respeito ao conteúdo do sistema $\mathrm{ABO}$. Os resultados encontrados se assemelham aos apresentados por Aguiar $e t$ al. (2020), ao realizarem um trabalho com estudantes do Ensino Médio no município de Uruçuí-PI. Nesse sentido, ao questionarem os alunos sobre os conteúdos de maior dificuldade na Genética, os autores encontraram as seguintes respostas: 46,9\% afirmam ser "Sistema ABO/Alelos múltiplos", 15,6\% "Herança Quantitativa", 15,6\% "Linkage", 12,5\% "Herança Sexual" e 9,4\%, "2a Lei de Mendel".

São inúmeras as dificuldades encontradas por professores de Biologia ao ensinarem o conteúdo do sistema ABO. A Tabela 2 mostra as principais dificuldades relatadas pelos participantes em relação ao processo de ensino de Genética, investigado em nosso estudo. Dentre os relatos, destaca-se a falta de materiais interativos (34\%), que está associada à complexidade do conteúdo (23\%).

Ao realizarem um estudo em uma Escola Estadual na região metropolitana de Belo Horizonte, Minas Gerais, Souza $e t$ al. (2017) constataram que a principal dificuldade encontrada no ensino aprendizagem desse conteúdo é o fato de o mesmo ser 
muito complexo e abstrato, o que de certa forma se assemelha aos relatos dos participantes do presente estudo.

Tabela 2 - Dificuldades dos alunos em relação ao conteúdo de genética de acordo com o relato dos participantes da pesquisa.

\begin{tabular}{|c|c|c|}
\hline Respostas & Professores & $\%$ \\
\hline Falta de materiais interativos & 9 & $34 \%$ \\
\hline Complexidade do conteúdo & 6 & $23 \%$ \\
\hline Muito conceitual (ensino abstrato) & 3 & $12 \%$ \\
\hline Baixo interesse dos alunos & 3 & $12 \%$ \\
\hline Não tenho dificuldades & 5 & $19 \%$ \\
\hline
\end{tabular}

Fonte: Autores (2021).

Em se tratando da participação dos alunos durante as aulas do sistema sanguíneo, a maioria dos entrevistados afirmaram que os alunos têm, relativamente, uma boa participação (54\%), seguido daqueles que classificaram como mediana (38\%) e ótima (8\%). A participação do aluno no decorrer da aula depende diretamente de como o docente administra o conteúdo abordado, visto que na maioria dos casos, os alunos se dispersam e deixam de participar quando o professor se prende muito ao material didático e ao conteúdo, não proporcionando uma contextualização das informações trabalhadas (Souza, 2019). Assim, é importante que os docentes desenvolvam meios para que os alunos não se dispersem, tais como o uso de atividades práticas e atividades inseridas na vivência dos mesmos.

A literatura apresenta várias descrições acerca das dificuldades de professores e alunos no aprendizado do sistema $\mathrm{ABO}$ (Costa, 2019; Prado et al., 2015; Souza et al., 2017), bem como a importância do uso de metodologias não tradicionais no ensino da biologia (Marin \& Júnior, 2020; Nicola \& Paniz, 2017; Santos, et al., 2020). Dessa forma, não nos limitamos apenas à observação da realidade, mas ao mesmo tempo, confeccionamos uma ferramenta didática facilitadora na construção do conhecimento relacionada ao sistema $\mathrm{ABO}$, que foi avaliada por docentes de Biologia da Educação Básica. De acordo com os resultados, 92\% aprovaram o modelo e pretendem utilizá-lo nas aulas; um deles gostou, mas não tem interesse em usar (4\%), e apenas um dos participantes (4\%) não gostou.

Novas técnicas são necessárias não só para melhorar o ensino, mas também para permitir meios dos docentes obterem a atenção de seus alunos. Durante as aulas de Genética surgem diversos questionamentos sobre os conteúdos e mesmo com todo empenho do professor em explanar o tema, os alunos ainda continuam com inúmeras incertezas. Por isso, ferramentas didáticas que permitam a visualização de conceitos antes só imagináveis contribuem diretamente com a qualidade do ensino em Biologia (Nicola \& Paniz, 2017).

Dessa forma, ao serem questionados se o modelo didático confeccionado poderia vir a ajudar no processo de ensinoaprendizagem no conteúdo de Genética, $92 \%$ dos professores responderam que sim, em detrimento aos $8 \%$ dos professores que responderam que não facilitaria. Para Setúval \& Bejarano (2009), a criação de modelos didáticos com conteúdos de Genética permite reflexões sobre o seu processo de construção e de aplicação experimental, bem como contribui para práticas pedagógicas no ensino de Ciências e Biologia, refletindo na construção do conhecimento no processo de ensino-aprendizagem.

\section{Conclusão}

Os conteúdos de Genética podem se favorecer de metodologias alternativas que visem aproximar os conteúdos trabalhados à realidade dos educandos. A falta de estrutura e/ou recursos necessários ao desenvolvimento de aulas práticas acabam desestimulando os docentes e discentes. No entanto, a ausência de laboratórios e equipamentos especializados não 
podem ser considerados fatores limitantes ao desenvolvimento de aulas mais interativas, sendo responsabilidade do professor a realização de estratégias metodológicas que visem suprir tais déficits, a exemplo da confecção de materiais didáticos.

$\mathrm{O}$ modelo didático do sistema $\mathrm{ABO}$ elaborado e avaliado neste estudo foi muito bem avaliado pelos docentes que participaram da pesquisa. Assim, espera-se que a proposta seja de fato implementada em sala de aula, proporcionando um efetivo processo de ensino-aprendizagem. Nesse contexto, espera-se, ainda, que a pesquisa sirva de suporte para o desenvolvimento de novos estudos, especialmente no que diz respeito ao ensino de genética com base na confecção e aprimoramento dos modelos didáticos já existentes, os quais vêm se mostrando como uma alternativa economicamente viável para aproximar o aluno do conteúdo escolar.

\section{Referências}

Aguiar, K. A., \& Castro, I. F. A. (2020). A genética do ensino médio na perspectiva discente: um estudo de caso no município de Uruçuí-PI. International Journal Education and Teaching, 3(3), 102-116.

Arruda, E. H. P., Ortiz, T. A., \& Pinheiro, D. O. (2013). Importância do Autoconhecimento dos Grupos Sanguíneos (ABO e Rh) de Alunos de Tangará da Serra-MT. Unopar Científica Ciências Biológicas e da Saúde, 15(3), 199-202.

Augusto, T. G. D. S., \& Basilio, L. V. (2018). Ensino de biologia e história e filosofia da ciência: uma análise qualitativa das pesquisas acadêmicas produzidas no Brasil (1983-2013). Ciência \& Educação, 24(1), 71-93.

Brasil. Ministério da Educação. (1996). Lei $n^{o}$ 9.394, de 20 de dezembro de 1996. Lei de Diretrizes e Bases da Educação Brasileira - LDB. http://www.planalto.gov.br/ccivil_03/leis/19394.htm.

Brasil. Ministério da Educação. (2017). Base Nacional Comum Curricular (BNCC): competências gerais da educação básica. MEC.

Brasil. Ministério da Educação. (1999). Parâmetros Curriculares Nacionais: ensino médio. MEC.

Carmo, B. B. S. (2018). O ensino dos conectores com uso de formulários do Google. EntreLetras, 9(2), 290-315.

Carvalho, C. S., Feliciano, F. J., Lucas, L. B. (2018). Abordagem metodológica de ensino na formação inicial de professores de Ciências e Biologia - enfoque histórico, filosófico da Ciência. RBECM, 1(2), 155-173.

Cipriano, T. H. A. S.; Silva, L. P.; Silva, D. C.; Bomfim, B. L. S. Concepções de alunos e professores da educação básica sobre a importância das aulas práticas no ensino-aprendizagem de biologia. IN: BOMFIM, B. L. S.; et al. BIOdiversidade: Educação, Saúde e Conservação. 1 ed. 2018.

Cirne, A. (2013). Dificuldades de aprendizagem sobre conceitos de genética no ensino fundamental. $269 f$. Dissertação (Mestrado em Ensino de Ciências Naturais e Matemática) Centro de Ciências Exatas e da Terra, Universidade Federal do Rio Grande do Norte, Rio Grande do Norte). https://repositorio.ufrn.br/jspui/handle/123456789/16113.

Duré, R. C., Andrade, M. J. D., Abílio, F. J. P. (2018). Ensino de biologia e contextualização do conteúdo: quais temas o aluno de ensino médio relaciona com o seu cotidiano. Experiências em Ensino de Ciências, 13(1), 259-271.

Fonseca, A. L. C., \& Tartarotti, E. (2017). Análise Praxeológica de Atividades sobre Polialelia e Grupos Sanguíneos no Livro Didático de Biologia. XI Encontro Nacional de Pesquisa em Educação em Ciências, 11(1), 1-10.

Fontelles, M. J., Simões, M. G., Farias, S. H., \& Fontelles, R. G. S. (2009). Metodologia da pesquisa científica: diretrizes para a elaboração de um protocolo de pesquisa. Revista paraense de medicina, 23(3), 1-8.

Heidemann, L. A., Oliveira, A. M. M. D., \& Veit, E. A. (2010). Ferramentas online no ensino de ciências: uma proposta com o Google Docs. Física na escola, 11(2), 30-33.

Klautau-Guimarães, M. N., Bonadio, R. S., Paiva, S. G. (2015). Ensino e aprendizagem de conceitos em genética: a divisão celular. X Encontro Nacional de Pesquisa em Educação em Ciências, 10(1), 01-06.

Kenski, V.M. (2012). Educação e Tecnologias: O novo ritmo da informação. Editora Papirus, 141p.

Rocha, L. D. L. S., Faria, J. C. N. M., Cruz, A. H. S., Reis, A. A. S., Santos, R. S. (2013). Drosophila: um importante modelo biológico para a pesquisa e o ensino de Genética. Scire Salutis, 3(1), 37-48.

Lucas, L. B., (2015). Da didática geral aos procedimentos de ensino: uma visão sistematizada dos componentes da prática docente. In: Rocha, Z. de Fátima D. C. et al. (Org.). Propostas didáticas inovadoras: produtos educacionais para o ensino de ciências e humanidades. Maringá, PR: Gráfica Editora Almeida.

Marin, G. R. B., \& Júnior, A. J. V. (2020). Contribuições da construção de jogos digitais para o ensino de Genética. Revista de Estudos e Pesquisas sobre Ensino Tecnológico, 6(1), 1-17.

Medeiros, F. V. G., Rodrigues, M. J. A. M., Cavalcante, C. A. M. (2017). A formação e o perfil dos professores de Biologia na cidade de Jaguaribe (Ceará, Brasil) e professores de Biologia e Geologia na cidade de Bragança (Portugal). In: Atas da 1. ${ }^{a}$ Conferência internacional Sociedade Portuguesa de Ciências da Educação: A educação comparada para além dos números: contextos locais, realidades nacionais e processos transnacionais. Sociedade Portuguesa de Ciências da Educação, Secção de Educação Comparada, 411-418. 
Nicola, J. A. \& Paniz, C. M. (2017). A importância da utilização de diferentes recursos didáticos no Ensino de Ciências e Biologia. InFor, 2(1), 355-381.

Nunes, F. L. (2016). Aplicação do peer instruction no ensino tecnológico superior com o auxílio do google forms: um estudo de caso. Anais do XXIII SIMPEP-Simpósio de Engenharia de Produção, 18(1), 204-205.

Costa, N. A. F., Oliveira, A. C. S., Barroso, A. G. F. S., Costa, K. L. S., Paiva, R. C., Valadares, B. L. B. (2019). Praticando que se aprende: identificando os tipos sanguã neos de discentes do $1^{\circ}$ ano do ensino medio. Scientia plena jovem, 6(2), 1-10.

Oliveira, A.C.F.K. \& Silva, F. A. R. (2016). O curso de especialização em ensino de ciências e sua contribuição na formação de professores. Revista da SBEnBio, 9(1), 692-703.

Pierce, B. (2016). Genética: Um enfoque conceitual. Guanabara Koogan, 2016.

Prado, R. O., Quintino, A. V., \& Barros, M. D. M. (2015). Conhecimentos prévios sobre o sistema ABO de alunos do terceiro ano do ensino médio de uma escola pública estadual do município de Betim, Minas Gerais, Brasil. VITTALLE-Revista de Ciências da Saúde, 27(1), 36-40.

Santos, A. L. C., Silva, F. V. C., Santos, L. G. T., \& Feitosa, A. A. F. M. A. (2020). Dificuldades apontadas por professores do programa de mestrado profissional em ensino de biologia para o uso de metodologias ativas em escolas de rede pública na paraíba. Brazilian Journal of Development, 6(4), 2195921973.

Setúval, F. A. R. \& Bejarano, N. R. R. (2009). Os modelos didáticos com conteúdos de genética e a sua importância na formação inicial de professores paa o ensino de ciências e biologia. In: VII Enpec - Encontro Nacional de Pesquisa em Ensino de Ciências. Anais. http://posgrad.fae.ufmg.br/posgrad/viienpec/pdfs/1751.pdf.

Silva, B. A. (2013). O uso pedagógico de TIC em Centro de Estudos de Língua, no ensino público de Assis/SP. Revista Tecnologias na Educação, 5(9), 1-14.

Silva, J. M. A., Canedo, R. V., Abrantes, T. A. S., Santos, R. T., Souza, R. A., Utagawa, C. Y. (2010). Quiz: um questionário eletrônico para autoavaliação e aprendizagem em genética e biologia molecular. Revista Brasileira de Educação Médica, 34(4), 607-614.

Soares, K. D. A. C., Pinto, M. C., Rocha, M. O. (2011). Cada lócus por si Mesmo: por onde andam esses Genes? In: GENÉTICA na sala de aula: estratégias de ensino e aprendizagem. PROMED/SEE/UFRJ.

Sousa, E. S. et al. (2016). A Genética Em Sala De Aula: Uma Análise Das Percepções E Metodologias Empregadas Por Professores Das Escolas Públicas Estaduais De Jaguaribe Ceará. Conex. Ci. e Tecnol. 10(4), 16-24.

Souza, A. C. R. S. (2019). Mitos sobre a relevância do ensino do sistema ABO e uma sequência didática visando minimizar equívocos acerca desse tema. 128 f. Dissertação (Mestrado Profissional em Ensino de Biologia em Rede Nacional). Universidade de Brasília. https://repositorio.unb.br/handle/10482/37378.

Souza, H. A., Ribeiro, P. A. C., Rocha, M. L., Ferreira, K. E., \& Costa, F. J. (2017). Memória Sanguínea: Uma atividade com alunos do EJA para fixar o conteúdo do Sistema ABO. Revista Ampliar, 3(3), 1-11.

Teodoro, N. C. Professores de Biologia e dificuldades com os conteúdos de ensino. 147 f. Dissertação (Mestrado em Educação para a Ciência). Universidade Estadual Paulista, Bauru, 2017.

Tompo, B., Ahmad, A., \& Muris. M. (2016). The Development of Discovery-Inquiry Learning Model to Reduce the Science Misconceptions of Junior High School Students. International Journal of Environmental and Science Education, 11(12), 5676-5686.

Trópia, G. (2011). Relações dos alunos com o aprender no ensino de Biologia por atividades investigativas. 202 f. Dissertação (Mestrado em Educação Científica e $\quad$ Tecnológica). Universidade Catarina. https://repositorio.ufsc.br/bitstream/handle/123456789/93177/266452.pdf?sequence=1\&isAllowed=y.

Valente, S. (2019). Influência da inteligência emocional na gestão de conflito na relação professor-aluno (s). Revista de Estudios e Investigación en Psicología y Educación, 6(2), 101-113. 